\title{
Plasticity of Metabotropic Glutamate Receptor-Dependent Long-Term Depression in the Anterior Cingulate Cortex after Amputation
}

\author{
SukJae Joshua Kang, ${ }^{1}$ Ming-Gang Liu, ${ }^{1}$ Tao Chen, ${ }^{2}$ Hyoung-Gon Ko, ${ }^{3}$ Gi-Chul Baek, ${ }^{3}$ Hye-Ryeon Lee, ${ }^{3}$ Kyungmin Lee, ${ }^{4}$ \\ Graham L. Collingridge, ${ }^{1,5}$ Bong-Kiun Kaang, ${ }^{1,3}$ and Min Zhuo ${ }^{1,2}$ \\ ${ }^{1}$ Department of Brain and Cognitive Sciences, College of Natural Sciences, Seoul National University, Seoul 151-746, Korea, ${ }^{2}$ Department of Physiology, \\ Faculty of Medicine, University of Toronto, Toronto, Ontario M5S 1A8, Canada, ${ }^{3}$ National Creative Research Initiative Center for Memory, Department of \\ Biological Sciences, College of Natural Sciences, Seoul National University, Seoul 151-747, Korea, ${ }^{4}$ Department of Anatomy, Graduate School of Medicine, \\ Brain Science \& Engineering Institute, Kyungpook National University, Daegu 700-422, Korea, and ${ }^{5}$ Medical Research Council Centre for Synaptic \\ Plasticity, School of Physiology and Pharmacology, University of Bristol, Bristol BS8 1TD, United Kingdom
}

Long-term depression (LTD) is a key form of synaptic plasticity important in learning and information storage in the brain. It has been studied in various cortical regions, including the anterior cingulate cortex (ACC). ACC is a crucial cortical region involved in such emotion-related physiological and pathological conditions as fear memory and chronic pain. In the present study, we used a multielectrode array system to map cingulate LTD in a spatiotemporal manner within the ACC. We found that low-frequency stimulation ( $1 \mathrm{~Hz}, 15$ $\mathrm{min}$ ) applied onto deep layer V induced LTD in layers II/III and layers V/VI. Cingulate LTD requires activation of metabotropic glutamate receptors (mGluRs), while L-type voltage-gated calcium channels and NMDA receptors also contribute to its induction. Peripheral amputation of the distal tail impaired ACC LTD, an effect that persisted for at least 2 weeks. The loss of LTD was rescued by priming ACC slices with activation of mGluR1 receptors by coapplying (RS)-3,5-dihydroxyphenylglycine and MPEP, a form of metaplasticity that involved the activation of protein kinase C. Our results provide in vitro evidence of the spatiotemporal properties of ACC LTD in adult mice. We demonstrate that tail amputation causes LTD impairment within the ACC circuit and that this can be rescued by activation of mGluR1.

\section{Introduction}

Human and animal studies consistently demonstrate that neurons in the anterior cingulate cortex (ACC) play important roles in pain perception and chronic pain conditions (for review, see Vogt, 2005; Zhuo, 2008). Brain imaging studies demonstrate that ACC and its related cortical areas are activated by acute nociceptive stimuli (Talbot et al., 1991; Craig et al., 1996; Rainville et al.,

Received Jan. 11, 2012; revised June 25, 2012; accepted June 29, 2012.

Author contributions: S.J.K., K.L., G.L.C., B.-K.K., and M.Z. designed research; S.J.K., M.-G.L., T.C., H.-G.K., and G.-C.B. performed research; H.-R.L. contributed unpublished reagents/analytic tools; S.J.K. and G.-C.B. analyzed data; S.J.K., T.C., K.L., G.L.C., and M.Z. wrote the paper.

This work was supported by the World-Class University (WCU) program of the Ministry of Education, Science and Technology in Korea through the National Research Foundation (R32-10142). S.J.K., G.C.B., and H.-R.L. were supported by BK21 fellowships. M.Z. was supported by the Canada Research Chair (CRC), Natural Sciences and Engineering Research Council of Canada Discovery Grant 402555, and the WCU. K.L. was supported by Basic Science Research Program (2011-0028240) through the National Research Foundation of Korea. H.G.K. was supported by a National Research Foundation of Korea grant funded by the Korean Government (Ministry of Education, Science and Technology, NRF-2011-35B-C00034). B.-K.K. is a Yonam Foundation Scholar and supported by the WCU and the National Creative Research Initiative Program, Korea. G.L.C. was supported by the Medical Research Council.

The authors declare no competing financial interests.

Correspondence should be addressed to either of the following: Bong-Kiun Kaang at National Creative Research Initiative Center for Memory, Department of Biological Sciences, College of Natural Sciences, Seoul National University, 599 Gwanangno, Gwanak-gu, Seoul 151-747, Korea, E-mail: kaang@snu.ac.kr; or Min Zhuo at Department of Physiology, Faculty of Medicine, University of Toronto, 1 King's College Circle, Toronto, Ontario M5S 1A8, Canada, E-mail:min.zhuo@utoronto.ca.

DOI:10.1523/JNEUROSCI.0146-12.2012

Copyright $\odot 2012$ the authors $\quad 0270-6474 / 12 / 3211318-12 \$ 15.00 / 0$
1997; Strigo et al., 2003; Dunckley et al., 2005). ACC can be also activated during the empathy of pain, social rejection, and other psychological pain conditions (Eisenberger et al., 2003; Singer et al., 2004; de Tommaso et al., 2005). ACC has been reported to be activated in different chronic pain conditions (Apkarian et al., 2005; Zhuo, 2008, 2011). Inactivation of the ACC, by surgical lesions or cell death caused by stroke, leads to the reduction of the unpleasantness of pain or reduced pain intensity (Pillay and Hassenbusch, 1992; Wong et al., 1997; Yen et al., 2005, 2009). Electrophysiological recording from human shows that many ACC neurons are indeed nociceptive (Hutchison et al., 1999). Animal studies of the ACC not only confirm the importance of ACC in nociception (Vogt, 2005; Zhuo, 2008, 2011), but also reveal molecular mechanisms for chronic pain (Zhuo, 2006, 2008). While peripheral injury triggers activity-dependent immediate early genes (Zhuo, 2006, 2011) and induces long-term potentiation (LTP) of excitatory synaptic responses in the ACC neurons (Wei and Zhuo, 2001; Xu et al., 2008), inhibition or genetic deletion of key molecules required for triggering LTP produces analgesic effects in animal models of chronic pain (Wei et al., 2002; Wu et al., 2005b; Wang et al., 2011). Recently, protein kinase $\mathrm{M} \zeta(\mathrm{PKM} \zeta)$ has been identified as a key enzyme required to maintain such injury-related LTP (Li et al., 2010).

In addition to LTP, long-term depression (LTD) has been also implicated in various brain functions (for review, see Bliss and 
A

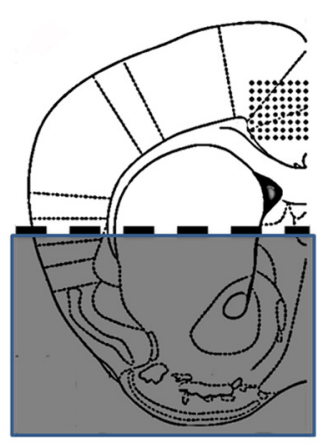

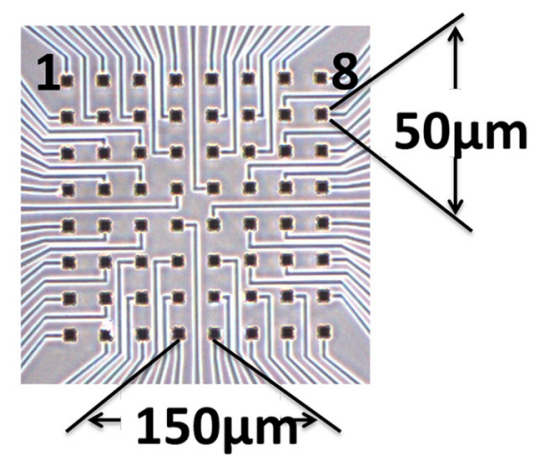

B

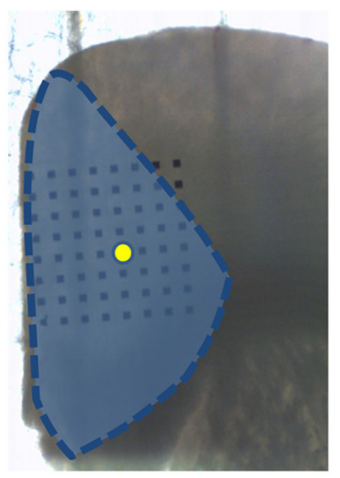

C Ch. 29
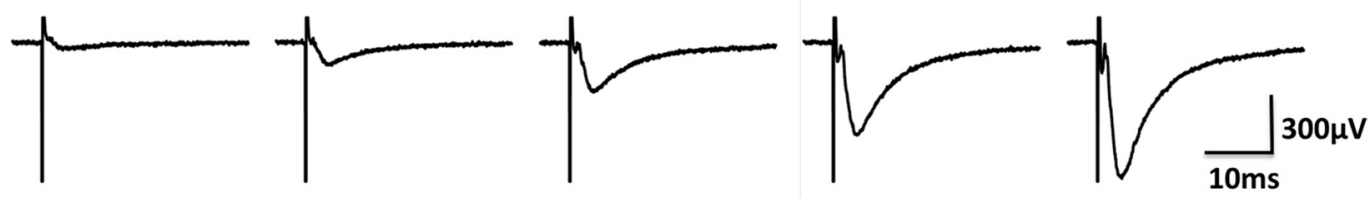

D

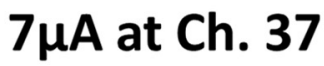

\section{E $9 \mu \mathrm{A}$ at Ch. 37}


$\mathbf{F}$

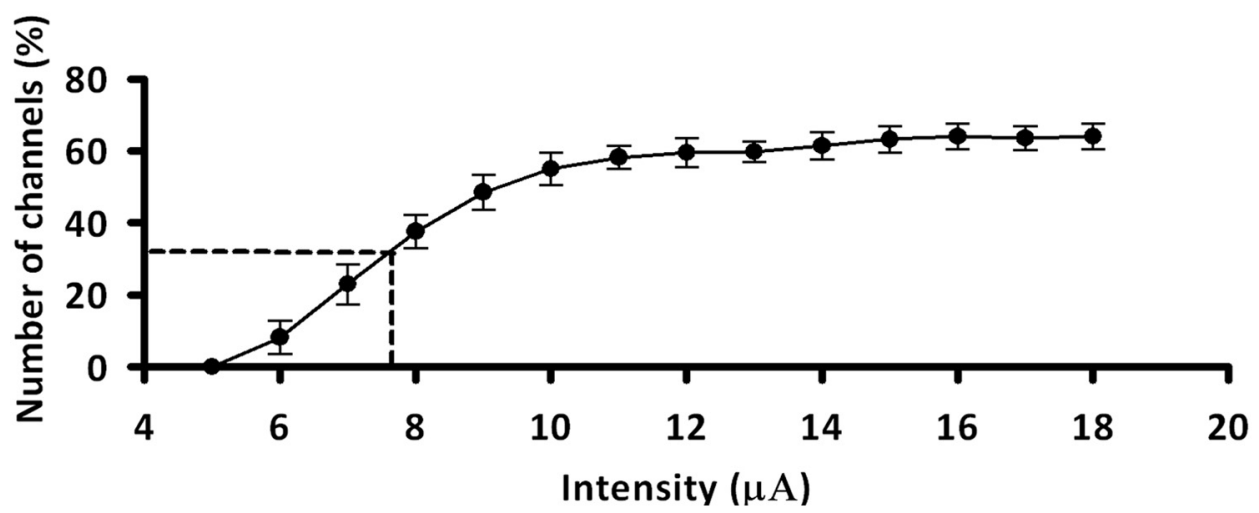

Figure 1. Spatial distribution of excitatory synaptic transmission in the ACC on a multielectrode array. $A$, Schematic diagram of an ACC slice placement on the MED64 probe, and the scale of the electrodes. The dark region in the slice is removed before recording. $\boldsymbol{B}$, Light microscopy photograph showing ACC and the MED64 probe electrodes. The blue region is the ACC and the yellow circle is the electrode (Channel 37) that is stimulated. Example traces on the graph indicate the responses in the numbered period. $C$, Intensity-dependent fEPSPs $(5-9 \mu \mathrm{A})$ in one specific channel above the stimulation site (Channel 29). D, E, All channel fEPSPs when stimulating channel 37 (yellow lightning bolt) with 7 and $9 \mu$ A. The number of channels exhibiting a response and the amplitude of the fEPSPs increased with raised stimulus intensities. The spreading of the fEPSPs displays the network in the ACC. $F$, The number of activated channels increased as the input intensity was raised ( $n=6$ slices/3 mice). The effective intensity to induce $50 \%$ of the maximum (dashed line) was $7.4 \mu \mathrm{A}$. The number of activated channels became saturated $\sim 12 \mu \mathrm{A}$.

Cooke, 2011). Two major types of LTD have been discovered: NMDA receptor-dependent LTD and NMDA receptor-independent LTD [or metabotropic glutamate receptor-dependent LTD, (mGluR-LTD)]. These two forms of LTD are triggered by different induction protocols and underlie different physiological/ pathological functions (Collingridge et al., 2010), such as learning and memory (Manahan-Vaughan and Braunewell, 1999), behavioral flexibility (Nicholls et al., 2008; Kim et al., 2011), fragile X syndrome (Dölen et al., 2007), and drug addiction (Brebner et al., 2005). LTD has also been described in the ACC (Toyoda et al., 2005, 2007). In adult rats with single-digit amputation, ACC LTD was impaired (Wei et al., 1999). 
In the present study, we used a 64channel multielectrode dish (MED64) system, a two-dimensional electric activity monitoring device, to characterize LTD in adult mouse ACC. The MED64 system enabled us to detect the field EPSP (fEPSP) at multiple sites in mouse ACC, which is difficult to achieve with conventional field recording systems. We found that low-frequency stimulation induced mGluR-dependent LTD at the network level, and suggest the possible utility of targeting the mGluR 1 for future treatment of patients with amputation-related pain.

\section{Materials and Methods}

Animals. Adult (8-12-week-old) male C57BL/6 mice (Orient Bio) were used. All animals were housed under a $12 \mathrm{~h}$ light/dark cycle with food and water provided ad libitum. All works were conducted according to the policy and regulation for the care and use of laboratory animals approved by Institutional Animal Care and Use Committee at Seoul National University.

Amputation surgical procedure. C57BL/6 mice were gently anesthetized with isoflurane. Then a $2.5 \mathrm{~cm}$ length of the tail was removed (see Fig. 7A). Locktight instant glue was used to stop bleeding. For sham surgery mice, only the anesthesia procedure was carried out. Two weeks later, all mice were killed for the preparation of brain slices.

Brain slice preparation. Adult male mice were anesthetized with isoflurane and the brains were removed and transferred to icecold artificial CSF (ACSF) containing (in $\mathrm{mm}$ ): $124 \mathrm{NaCl}, 2.5 \mathrm{KCl}, 2 \mathrm{CaCl}_{2}, 2 \mathrm{MgSO}_{4}, 25$ $\mathrm{NaHCO}_{3}, 1 \mathrm{NaH}_{2} \mathrm{PO}_{4}$, and 10 glucose, $\mathrm{pH}$ 7.4. This ACSF was used throughout the experiment. Three coronal brain slices $(300 \mu \mathrm{m})$, after the corpus callosum meets and contains ACC, were cut using a vibratome (Leica VT 1000S). The slices were placed in a submerged recovery chamber with oxygenated $\left(95 \% \mathrm{O}_{2}\right.$, $5 \% \mathrm{CO}_{2}$ ) ACSF at $26^{\circ} \mathrm{C}$ for at least $2 \mathrm{~h}$.

Preparation of the multielectrode array. The multielectrode array (MEA) system used in the current study was MED64 (Panasonic). The procedures for preparation of the MED64 system were similar to those of Oka et al. (1999). The MED64 probe (MED-P515A, $8 \times$ 8 array, interpolar distance $150 \mu \mathrm{m}$, Panasonic) was superfused with ACSF at $28-30^{\circ} \mathrm{C}$ and maintained at a $2-3 \mathrm{ml} / \mathrm{min}$ flow rate. One planar microelectrode with monopolar constant-current pulses (5-18 $\mu \mathrm{A}$, $0.2 \mathrm{~ms}$ ) was used for stimulation of the ACC slice. The stimulation site was selected within the deep layer $V$ region. Before use, the surface of the MED64 probe was treated with $0.1 \%$ polyethyleneimine (Sigma-Aldrich) in 25 $\mathrm{mmol} / \mathrm{L}$ borate buffer, $\mathrm{pH} 8.4$, overnight at room temperature.

Field potential recording in adult ACC slices. After $2 \mathrm{~h}$ recovery, one ACC slice was placed in a MED64 probe covering most of the 64 electrodes. The slice was allowed to recover for $1 \mathrm{~h}$ after transfer. Electrical stimulation was delivered to one channel located within the deep layer V of the ACC, and evoked fEPSPs were monitored and recorded from the other 63 channels. The intensity of the stimuli was $\sim 60-70 \%$ of the intensity that induced the maximal number of re-

D

\section{After CNQX}
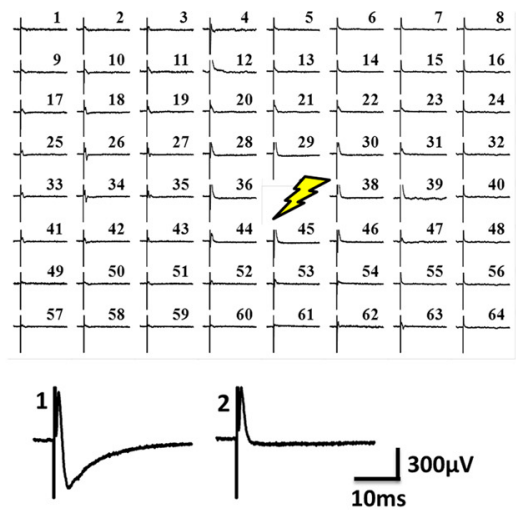

$(20 \mu \mathrm{M})$
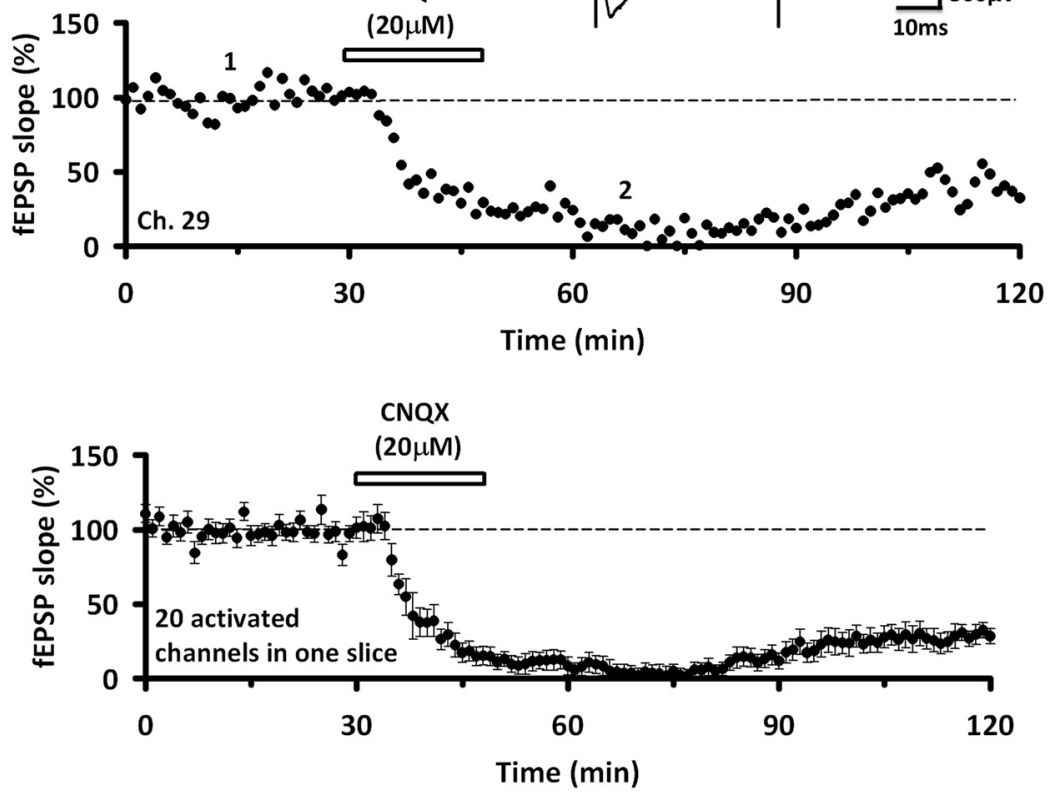

Time (min)

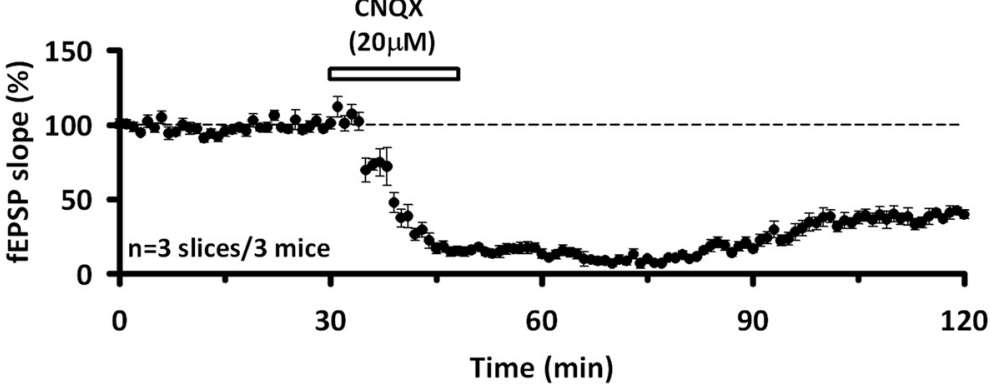

Figure 2. Glutamate-mediated synaptic transmission in the ACC. $A$, One sample of the fEPSPs of all channels before and after CNQX $(20 \mu \mathrm{M})$. Channel 37 was stimulated with $9 \mu \mathrm{A}$ (yellow lightning bolt). $\boldsymbol{B}$, Result of one channel in the CNQX experiment (Channel 29). Inset traces show representative fEPSPs at the time points indicated by the numbers in the graph. $C$, Summary result of 20 activated channels in one slice. D, Summary result of in all CNQX experiments ( $n=3$ slices $/ 3$ mice).

sponding channels determined by the input-output curve. Baseline responses were evoked at $0.017 \mathrm{~Hz}$ for at least 30 min before $1 \mathrm{~Hz}$ stimulation was given for $15 \mathrm{~min}$ to induce LTD (total pulses, 900). All other lowfrequency stimulation $(3,5$, and $10 \mathrm{~Hz}$ ) protocols also gave 900 pulses. In most experiments, $4-5$ channels near the stimulation site were selected for data analysis due to its reliable LTD induction probability. The averaged value of those channels was counted as one sample. All of the data were averaged every 4 min except the data from experiments where (RS)-3,5dihydroxyphenylglycine (DHPG) was applied. In those experiments, data were averaged every $2 \mathrm{~min}$.

Drugs. Drugs were prepared as stock solutions for frozen aliquots at $-20^{\circ}$ C. 6-Cyano-7-nitroquinoxaline-2,3-dione (CNQX, $20 \mu \mathrm{M}$ ), nimo- 


\section{A Baseline}

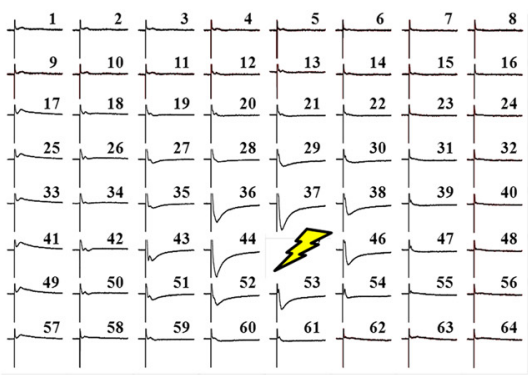

\section{After LFS}

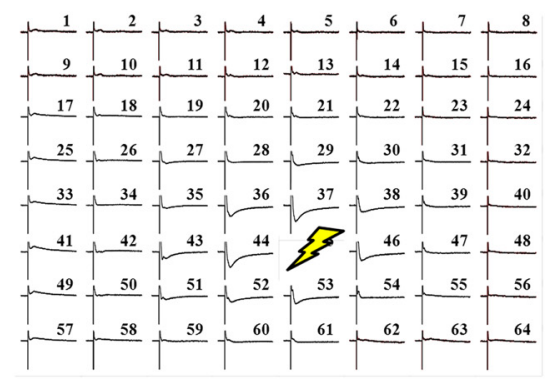

B

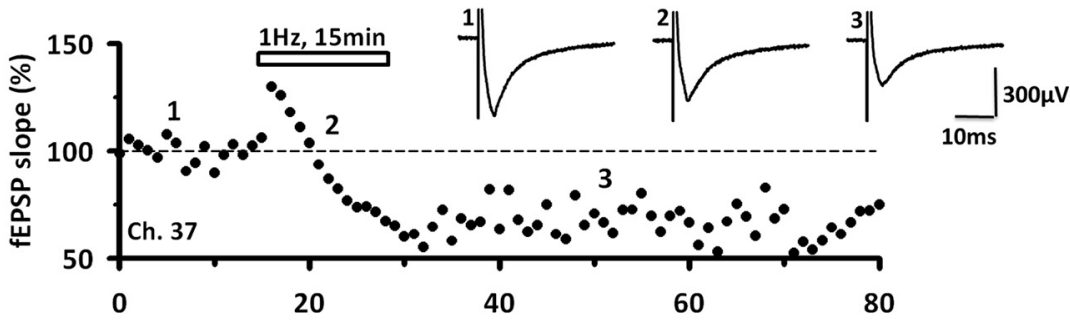

Time $(\min )$

C

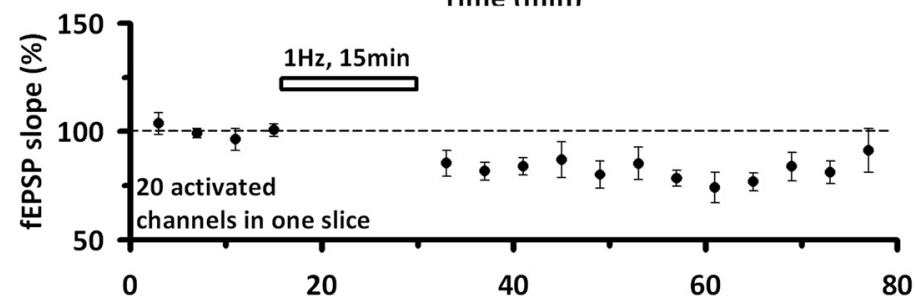

D



Figure 3. Low-frequency stimulation induces cortical LTD in the ACC. $A$, One sample of the fEPSPs during baseline (before) and 20 min after end of low-frequency stimulation ( $1 \mathrm{~Hz}, 15 \mathrm{~min}$ ). Channel 45 was stimulated (yellow lightning bolt). The amplitude of the fEPSPs in many channels decreased. $\boldsymbol{B}$, Result of one channel that showed LTD (Channel 37). $\boldsymbol{C}$, Summary of fEPSP slope of 20 activated channels in one slice $(87 \pm 8 \%)$. D, Summary data of $4-6$ channels surrounding the stimulation site show more stable result $(75 \pm 3 \% ; n=5$ slices $/ 5$ mice).

dipine (10 $\mu \mathrm{M}), \mathrm{D}(-)$-2-amino-5-phosphonopentanoic acid (AP-5, $50 \mu \mathrm{M}$ ), (+)- $\alpha$-methyl-4-carboxylphenlyglycine (MCPG, $500 \mu \mathrm{M}$ ), DHPG (20 or 100 $\mu \mathrm{M}), 2$-methyl-6-(phenylethynyl)pyridine hydrochloride (MPEP, $10 \mu \mathrm{M}$ ), (S)-(+)- $\alpha$-amino-4-carboxy-2-methylbenzeneacetic acid (LY367385, 100 $\mu \mathrm{M})$, chelerythrine chloride $(3 \mu \mathrm{M}), \mathrm{KN} 62(10 \mu \mathrm{M})$, and KT $5720(1 \mu \mathrm{M})$ were used in the current study. Drugs used in Figure 6 were applied throughout the entire experiment. Others were infused during the period of the horizontal bar on the graphs. AP-5, nimodipine, MCPG, CNQX, chelerythrine chloride, KN 62, KT 5720 were purchased from Tocris Bioscience. DHPG, MPEP, and LY367385 were purchased from Abcam Biochemicals.

Western blot analysis. Two $500 \mu \mathrm{m}$ slices, prepared as for the electrophysiological experiments, were used per mouse and pooled data from two mice were counted as one sample. The ACC tissue was then inserted into e-tubes and placed in liquid nitrogen. The four dissected ACC regions were then homogenized in TEVP buffer (10 mm Tris-Cl, pH 7.4, 1 mm EDTA, $1 \mathrm{~mm}$ EGTA, $320 \mathrm{~mm}$ sucrose) containing PIC (protease inhibitor cocktail; Roche). Part of the homogenate was used as a total fraction, and the rest was centrifuged at $1000 \times \mathrm{g}$ for $10 \mathrm{~min}$ for crude synaptosomal fraction- ation. The supernatant ( $\mathrm{S} 1$ fraction) was centrifuged again at $10,000 \times \mathrm{g}$ for $15 \mathrm{~min}$. After the supernatant [cytosol (S2) fraction] was transferred, the pellet [synaptosomal membrane (P2) fraction] was resuspended in RIPA buffer (50 mm Tris-Cl, pH 7.6, $150 \mathrm{~mm} \mathrm{NaCl,} 1$ mм EDTA, 1\% NP-40, 0.1\% SDS, 1 mм DTT, $0.5 \%$ sodium deoxycholate) containing PIC. Protein quantity for each fraction was determined by Bradford assay and then samples were heated at $95^{\circ} \mathrm{C}$ for $5 \mathrm{~min}$ in SDS-gel loading buffer [50 mm Tris-Cl, pH 6.8, 100 mm dithiothreitol, $2 \%(\mathrm{w} / \mathrm{v}$ ) SDS, $0.1 \%$ bromophenol blue, $10 \%$ $(\mathrm{v} / \mathrm{v})$ glycerol]. For electrophoresis, equal amount of protein was loaded to $8 \%$ polyacrylamide gels. Separated proteins were then transferred onto nitrocellulose membrane at $4^{\circ} \mathrm{C}$ for $17 \mathrm{~h}$. After $1 \mathrm{~h}$ blocking with 5\% skim milk in Tris-buffered saline containing Tween 20 at room temperature, membranes were incubated in appropriate primary antibodies, mGluR1 (1: 1000, BD Biosciences) and actin (1:5000, SigmaAldrich), at $4^{\circ} \mathrm{C}$ overnight. HRP-conjugated secondary antibodies were applied for $1 \mathrm{~h}$ at room temperature after washing. Enhanced chemiluminescence (Millipore) was used for detection of the proteins. Images were acquired by ChemiDoc XRS + System (Bio-Rad) and the density of the blots was measured using the Image Lab program (Bio-Rad).

Biotinylation assay. Four slices $(300 \mu \mathrm{m})$ containing the ACC region from one mouse were counted as one sample. These were used for examining surface mGluR1 level using biotinylation assay. After $1 \mathrm{~h}$ recovery, slices were incubated with $1 \mathrm{mg} / \mathrm{ml}$ sulfo-NHS-SS-biotin (Thermo) in ice-cold ACSF for $45 \mathrm{~min}$ at $4^{\circ} \mathrm{C}$. Then, slices were washed briefly with ice-cold ACSF and quenched by two 20 min washes at $4^{\circ} \mathrm{C}$ with $100 \mathrm{~mm}$ glycine in ice-cold ACSF. After brief wash in ice-cold TBS two times, the ACC region was dissected for crude synaptosomal fractionation. The $\mathrm{P} 2$ fraction was prepared with RIPA buffer containing PIC and protein phosphatase inhibitor cocktail followed by measurement of protein concentration using BCA protein assay (Thermo). Thirty microliters of NeutrAvidin agarose resin (Thermo) was washed three times with wash buffer (50 mM Tris-Cl, pH 7.6, $150 \mathrm{~mm} \mathrm{NaCl}$ ). The P2 lysate was incubated in washed beads for $3 \mathrm{~h}$ at $4^{\circ} \mathrm{C}$ followed by five washes with wash buffer. Finally, biotinylated proteins were eluted by incubation with SDS-gel loading buffer for $5 \mathrm{~min}$ at $95^{\circ} \mathrm{C}$. Eluted proteins were used for Western blot analysis. Pan-cadherin antibody (Santa Cruz Biotechnology) was used for loading control. Surface mGluR1 level was normalized by total mGluR1 level.

Data analysis. MED64 Mobius was used for data acquisition and analysis. All data are presented as mean \pm SEM. The percentages of the fEPSP slopes were normalized by the averaged value of the baseline (15-30 min). The depression levels used in histograms are the averaged fEPSP slope value of the last $10 \mathrm{~min}$ of the experiment. We defined LTD in a channel if the response was depressed by at least $15 \%$ of baseline during this period. Statistical comparisons were made using the $t$ test, one-way ANOVA, and Pearson product moment correlation test by SigmaPlot 11.0. Post hoc Bonferroni test was used for further comparison. If the data did not pass the equal variance test, one-way ANOVA was done in ranks and Dunn's method was used for post hoc test. In all cases, statistical significance was indicated by ${ }^{*} p<0.05,{ }^{* *} p<0.01,{ }^{* * *} p<0.001$. 


\section{Results}

Spatial distribution of extracellular responses in the ACC

In the present study, a 64-channel multielectrode array, MED64, was used to record the spatial distribution of extracellular field responses in the ACC of adult mice. An ACC slice was placed on top of the $8 \times 8$ square-shaped MED64 probe electrodes (Fig. $1 A)$. One channel that covered the deep layer V of ACC was chosen to stimulate the slice (Fig. $1 B$, yellow circle). fEPSPs recorded from the remaining 63 channels were intensitydependent. This could be seen in a single channel (Channel 29) and throughout the remaining channels (Fig. $1 C-E$ ). Most reliable fEPSPs were observed at recording sites located within 450 $\mu \mathrm{m}$ of stimulation site. The number of channels that show fEPSPs is also dependent on the intensity of the stimulation. In three mice ( 6 slices), we counted the number of channels generating a detectable fEPSP response over a stimulus intensity range varying from 5 to $18 \mu \mathrm{A}$. We found that the number of responsive channels reached a maximum at $12 \mu \mathrm{A}$ with $\sim 63 \%$ (on average, 40 of 63 channels) generating a detectable response (Fig. $1 F$ ). The effective intensity to induce $50 \%$ of the maximum number of channels $(32 \%)$ was $7.4 \mu \mathrm{A}$. In further experiments, we set the stimulus intensity (typically 8 or $9 \mu \mathrm{A}$ ) to achieve a baseline response that was $\sim 60-70 \%$ of the maximum.

\section{Glutamate-mediated synaptic transmission in the ACC}

Previous electrophysiological experiments have demonstrated that postsynaptic transmission in layer II/III of adult ACC is mediated by glutamatergic AMPA and kainate receptors in both rats and mice (Wei et al., 1999; Wu et al., 2005a). To confirm the pharmacological nature of fEPSPs, bath application of CNQX (20 $\mu \mathrm{M}, 20 \mathrm{~min}$ ), an AMPA/kainate receptor antagonist that effectively blocks fast synaptic transmission (Blake et al., 1988), was used to determine whether these receptors were the major mediators of excitatory synaptic transmissions in all layers of ACC. After bath applying CNQX, all the fEPSPs in the ACC were blocked (Fig. $2 A$ ), indicating that fEPSPs recorded in every layer of ACC are mediated by glutamate acting on AMPA/kainate receptors. The time course of the effect of CNQX in a singlechannel example (Channel 29; Fig. 2 B), the averaged fEPSPs of all activated 20 channels in a single slice (Fig. $2 C$ ) and the average of three mice $(n=3$ slices/ 3 mice; Fig. $2 D$ ) were identical. CNQX immediately blocked the responses, which started to partially recover 40 min after washout.

\section{Cortical depression induced by low-frequency stimulation within the ACC network}

There are several LTD-inducing protocols, such as low-frequency stimulation, pairing, spike-timing-dependent plasticity, and the application of chemicals (Collingridge et al., 2010). We chose the low-frequency stimulation protocol $(1 \mathrm{~Hz}, 15 \mathrm{~min})$ that has been used in various brain regions, such as hippocampus, visual cortex, and ACC (Dudek and Bear, 1992; Mulkey and Malenka, 1992; Kirkwood et al., 1993; Wei et al., 1999). As shown in previous reports in rat ACC (Wei et al., 1999), low-frequency stimulation also induces a long-lasting depression in the ACC of adult mice (Fig. $3 A, B$ ). However, not all activated channels underwent LTD. Therefore, the average value of fEPSP slope of the activated channels in one slice showed large variation $(87 \pm 8 \%$ of baseline in the last $10 \mathrm{~min}$ of the experiment, 20 channels in 1 slice; Fig. $3 C)$. The $4-6$ activated channels surrounding the stimulation site showed the highest chance of undergoing reliable LTD (75 $\pm 3 \%$, $n=5$ slices $/ 5$ mice; Fig. $3 D$ ).

\section{A One slice}

\section{Activated channels}

\section{LTD showing channels}
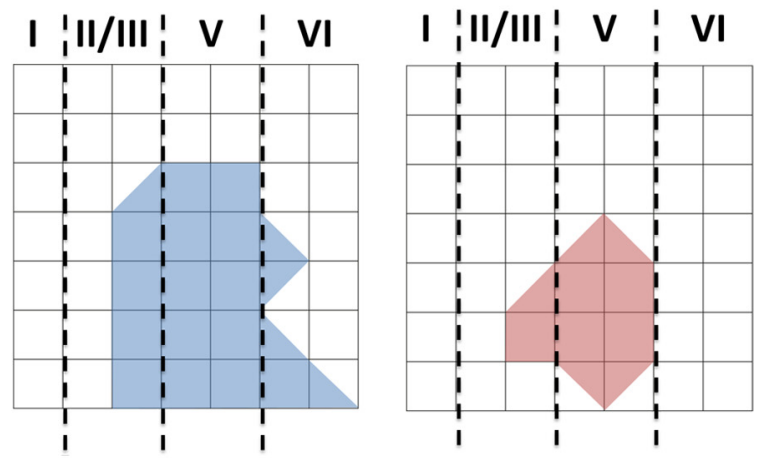

\section{B 6 slices}
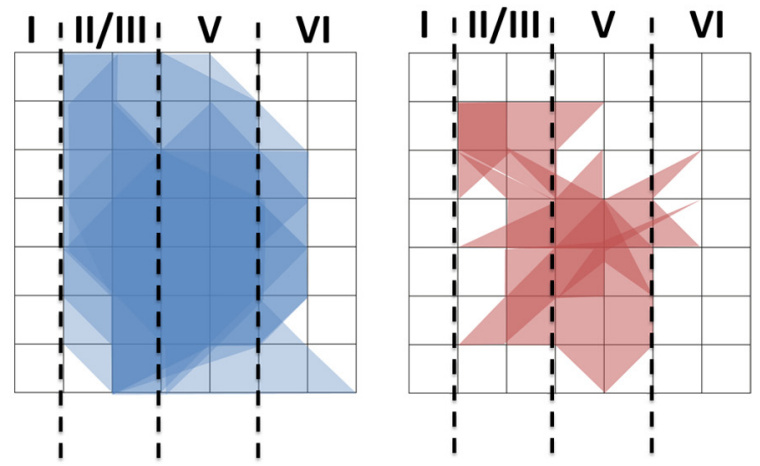

Figure 4. Spatial representation of ACC LTD. A, A polygonal diagram of the channels that were activated (blue) and that showed LTD (red). Grids represent the 64 channels in the MED64 probe. The vertical lines indicate the layers in the ACC slice. $\boldsymbol{B}$, Pooled data of six slices. The overlapped blue regions indicate frequently activated channels. The overlapped red regions indicate channels that frequently show LTD.

The use of the MED64 enabled us to quantify the cortical depression in a temporospatial manner. This is an important advantage of this recording method because previous studies in synaptic plasticity generally selected a single neuron or population of neurons to record and thus could not determine the network characteristics by electrophysiology. We defined LTD in a channel if the response was depressed by at least $15 \%$ of baseline during the last $10 \mathrm{~min}$ of the recording. One simple way to display the extent of LTD is by connecting the channels exhibiting LTD on a grid representing the $8 \times 8$ electrodes. The blue lines are the borderlines of the activated channels and the red lines are the borderlines for LTD-displaying channels for a single slice (Fig. $4 A$ ) and the pooled data $(n=6 / 6$; Fig. $4 B)$. The highest probability of observing LTD was in those channels surrounding the stimulation site. The surrounding channels in the layer II/III and V were also frequently exhibiting LTD. This could be observed by the most overlapped red region. We have also estimated the percentage of channels in these two categories. Not every activated channel went into LTD. During baseline, $30 \pm 3$ of 63 channels $(47 \pm 5 \%)$ were activated when giving $9 \mu \mathrm{A}$ and $13 \pm 1(20 \pm$ $2 \%)$ channels exhibited $\operatorname{LTD}\left(t_{(10)}=5.12, p<0.001 ; t\right.$ test $)$.

Frequency dependence of the induction of ACC LTD

We next investigated the frequency dependence of LTD by delivering 900 pulses at $1,3,5$, or $10 \mathrm{~Hz}$. We compared the level of depression for the different induction frequencies (Fig. 5A-E). 
A
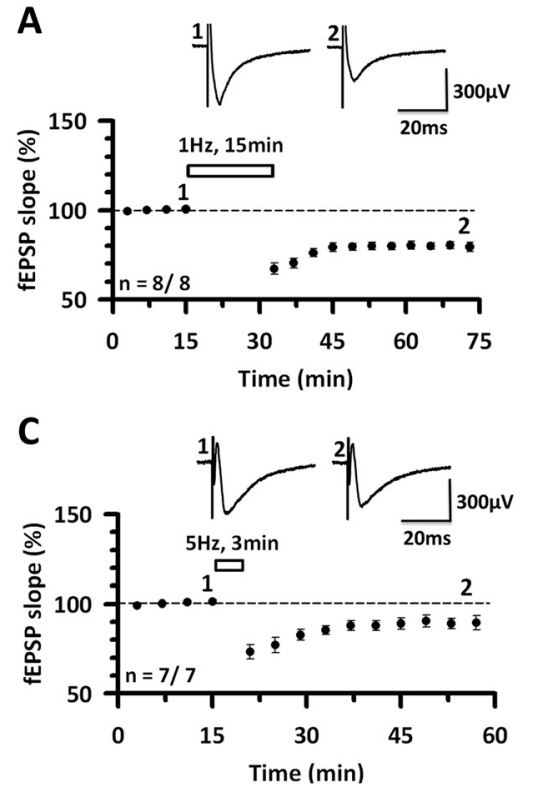

$\mathbf{E}$

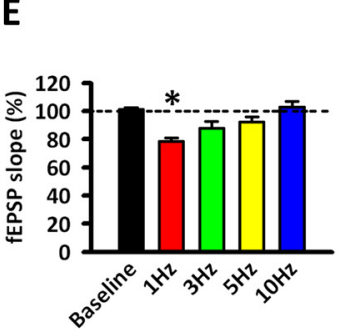

$\mathbf{F}$

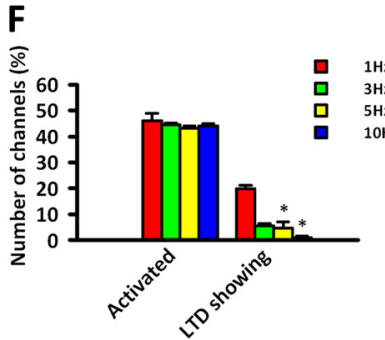

B

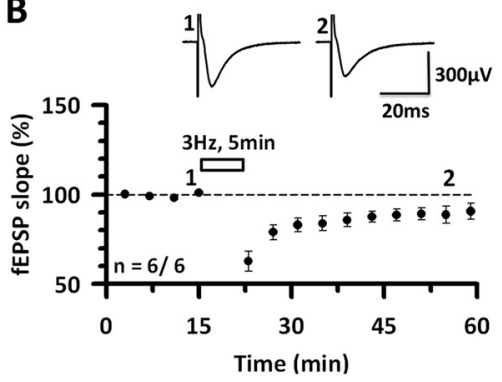

D

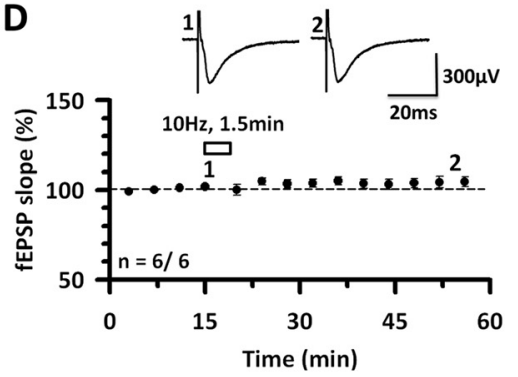

G

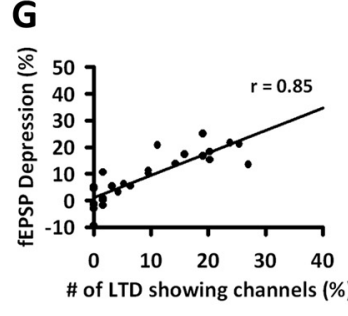

Figure 5. Frequency-dependent LTD in the ACC. $A$, Averaged data of LTD induced by $1 \mathrm{~Hz}, 15$ min stimulation ( $n=8$ slices/8 mice). Averaged fEPSP slope level of the last 10 min was $78 \pm 3 \%$. $\boldsymbol{B}$, Averaged data of $3 \mathrm{~Hz}, 5$ min for LTD induction $(88 \pm 5 \% ; n=$ 6 slices/ 6 mice). C, Averaged data of $5 \mathrm{~Hz}, 3 \mathrm{~min}$ for LTD induction ( $92 \pm 4 \% ; n=7$ slices $/ 7$ mice). D, Averaged data of $10 \mathrm{~Hz}, 1.5$ min showed no depression (103 $\pm 4 \% ; n=6$ slices/ 6 mice). $\boldsymbol{E}$, Summarized results of the averaged fEPSP slope level of the last 10 min following different frequencies of stimulation $\left(F_{(4,32)}=18.61, p<0.001\right.$; one-way ANOVA in ranks with Dunn's posthoc; $p<$ 0.05 for baseline vs $1 \mathrm{~Hz}$ ). $F$, Summarized results of the number of channels that were activated and that exhibited LTD (responses depressed by $>15 \%)$. Stimulation of $1 \mathrm{~Hz}$ showed the most LTD-showing channels $(18 \pm 3 \%)$. Stimulation of $3 \mathrm{~Hz}(6 \pm 2 \%)$ and $5 \mathrm{~Hz}(5 \pm 3 \%)$ showed fewer LTD-showing channels. Stimulation of $10 \mathrm{~Hz}(1 \pm 1 \%)$ had almost no LTD-showing channels $\left(F_{(3,23)}=15.38, p=0.002\right.$; one-way ANOVA in ranks with Dunn's post hoc; $p<0.05$ for $1 \mathrm{~Hz}$ vs $5 \mathrm{~Hz}$ and $\left.10 \mathrm{~Hz}\right)$. G, Linear correlation between fEPSP depression level and number of channels showing LTD. All four groups $(1,3,5$, and $10 \mathrm{~Hz})$ were used in the plot $\left(r_{(25)}=0.85, p<0.001\right.$; Pearson product moment).

Without giving any LTD-inducing protocol, "baseline" (101 \pm $1 \%, n=10$ slices/8 mice, data not shown) showed stable response. Stimulation at $1 \mathrm{~Hz}$ for $15 \mathrm{~min}$ showed great depression (78 $\pm 3 \%, n=8$ slices $/ 8$ mice). Stimulation at $3 \mathrm{~Hz}$ for $5 \mathrm{~min}$ $(88 \pm 5 \%, n=6$ slices $/ 6$ mice) and at $5 \mathrm{~Hz}$ for $3 \min (92 \pm 4 \%$, $n=7$ slices/7 mice) also showed some depression but not as much as the $1 \mathrm{~Hz}$ protocol. However, no depression was observed with stimulation at $10 \mathrm{~Hz}$ for $1.5 \mathrm{~min}(103 \pm 4 \%, n=6$ slices $/ 6$ mice) $\left(F_{(4,32)}=18.61, p<0.001\right.$; one-way ANOVA in ranks with Dunn's post hoc; $p<0.05$ for baseline vs $1 \mathrm{~Hz}$ ). Therefore, we could conclude that $1 \mathrm{~Hz}$ is most reliable to induce LTD in the mice ACC.

We also counted the number of channels activated during baseline, and showed LTD (Fig. $5 F$ ). All four groups had $\sim 45 \%$ activated channels. Stimulation at $1 \mathrm{~Hz}$ showed the most LTDshowing channels $(18 \pm 3 \%)$. Stimulation at $3 \mathrm{~Hz}(6 \pm 2 \%)$ and at $5 \mathrm{~Hz}(5 \pm 3 \%)$ showed fewer LTD-showing channels than 1 Hz. Stimulation at $10 \mathrm{~Hz}(1 \pm 1 \%)$ usually did not induce any LTD throughout the 63 channels $\left(F_{(3,23)}=15.38, p=0.002\right.$; one-way ANOVA in ranks with Dunn's post hoc; $p<0.05$ for $1 \mathrm{~Hz}$ vs 5 and $10 \mathrm{~Hz}$ ). Therefore, we could conclude that $1 \mathrm{~Hz}$ low- frequency stimulation, out of the four frequencies examined, showed the most reliable depression. We also found strong linear correlation graph between depression level and number of LTD-showing channels from the above experiments. Figure $5 G$ shows a strong positive correlation between the mean depression level and the percentage of channels displaying LTD $\left(r_{(25)}=0.85, p<0.001 ;\right.$ Pearson product moment).

\section{Pharmacological aspects of ACC LTD}

We next defined the glutamate receptor subtypes responsible for ACC LTD using pharmacological reagents. We used the NMDA receptor antagonist AP-5 (50 $\mu \mathrm{M})$, L-type voltage gated calcium channel (L-VGCC) blocker nimodipine (10 $\mu \mathrm{M})$, nonspecific mGluR blocker MCPG $(500 \mu \mathrm{M})$, the mGluR5 antagonist MPEP $(10 \mu \mathrm{M})$, and the mGluR1 antagonist LY367385 (100 $\mu \mathrm{M})$. We infused each drug for the entire experimental time (Fig. $6 A-G)$. Control experiment with no drug showed LTD after $1 \mathrm{~Hz}, 15 \mathrm{~min}$ lowfrequency stimulation $(78 \pm 2 \%, n=9$ slices $/ 9$ mice). AP- 5 partially blocked the depression $(88 \pm 2 \%, n=7$ slices $/ 7$ mice $)$, whereas both nimodipine $(95 \pm 3 \%, n=$ 6 slices $/ 6$ mice $)$ and MCPG $(93 \pm 3 \%, n=$ 6 slices 6 mice) blocked ACC LTD. MPEP did not affect LTD (77 $\pm 2 \%, n=4$ slices/4 mice). However, LY367385 effectively blocked LTD $(96 \pm 2 \%, n=5$ slices $/ 5$ mice $)\left(F_{(5,31)}=10.64, p<0.01\right.$; one-way ANOVA with Bonferroni post hoc; $p<0.001$ for control vs nimodipine, MCPG, and LY367385). These results suggest that L-VGCC and mGluR1 are important for the induction of lowfrequency-induced ACC LTD, while action of NMDA receptor also contributes to LTD in this region.

\section{Altered ACC cortical depression after tail amputation}

Recent studies show that cortical synaptic transmission undergoes long-term plastic changes after peripheral injury including amputation (Zhuo, 2008). To examine possible changes in the ACC LTD in adult mice after injury, we used the tail-amputation model (Fig. 7A). Slices were prepared at 2 weeks after amputation, a time where cortical changes have been reported previously (Wei et al., 1999). Sham mice showed normal LTD ( $81 \pm 2 \%, n=$ 7 slices $/ 7$ mice; Fig. $7 B$ ). However, in the amputated mice, LTD was abolished ( $96 \pm 2 \%, n=9$ slices/9 mice; Fig. $7 C$ ). This result is consistent with the previous rat digit amputation study (Wei et al., 1999). We also checked the spatial distribution of fEPSPs within the ACC after distal tail amputation and compared this with slices from sham mice (Fig. $7 D, E$ ). There was no difference between control and amputated group with respect to the number of channels exhibiting a synaptic response to test stimulation. Layer II/III and V channels were more consistently activated than layer VI channels in both cases. However, while half of the acti- 
vated channels in the control group underwent LTD, the amputated group rarely showed LTD throughout the channels.

Because the induction of ACC LTD is mGluR1-dependent, we next tested whether it was possible to induce LTD by pharmacological activation of mGluR1. To do this, we applied the group $1 \mathrm{mGluR}$ agonist DHPG $(100 \mu \mathrm{M})$ together with MPEP $(10 \mu \mathrm{M})$ so that it selectively activated mGluR1. As expected, bath application of DHPG and MPEP induced a longlasting depression in sham mice (86 \pm $4 \%, n=7$ slices/7 mice; Fig. $7 F$ ). However, consistent with the loss of LTD induced by electrical stimulation following tail amputation, this treatment failed to induce LTD in the amputated model ( $99 \pm 3 \%, n=8$ slices $/ 8$ mice; Fig. $7 G$ ). Therefore, these results suggest that both low-frequency stimulation-induced LTD and chemical LTD are blocked throughout all the layers of ACC in the tailamputated mice. In both forms of LTD, mGluR1 was essential; thus, we selected this as the target for further experiments.

\section{Rescuing ACC cortical depression after tail amputation}

Our electrophysiology experiments showed that ACC LTD was mGluR1dependent. One possible mechanism for the loss of LTD is reduced mGluR1 levels in amputated animals. To test this hypothesis, we performed Western blot analysis in the ACC to examine the effect of tail amputation on the expression level of mGluR1 (Fig. 8A). We found no difference in the mGluR1 expression level between sham and amputation group in total, S2 fraction, and $\mathrm{P} 2$ fraction. To further examine the surface mGluR1 level in the ACC, we performed biotinylation assay (Fig. $8 B$ ). There was no difference in the surface mGluR1 level between sham and tail amputated group (sham, $100 \pm 5 \%$; tail-amputated group, $98 \pm 5 \% ; n=8$ samples/ 8 mice).

In the hippocampus, there are reports that activation of mGluRs by DHPG has a priming effect on synaptic plasticity (so-called "metaplasticity"), especially on LTP (Abraham, 2008; Sajikumar and Korte, 2011). We were therefore interested to see whether priming can influence the ability to induce LTD in the tail-amputation model. Thus, we applied low-frequency stimulation to the slices $50 \mathrm{~min}$ after the end of selective activation of mGluR1 by DHPG plus MPEP. While DHPG plus MPEP did not induce any long-lasting depression in slices of amputated mice, subsequent low-frequency stimulation $(1 \mathrm{~Hz}, 15 \mathrm{~min})$ produced significant depression of fEPSPs in a single example (Fig. 9A) and in pooled data $(72 \pm 5 \%, n=8$ slices/ 8 mice; Fig. $9 B)$ that was similar to that observed in sham-treated mice. This result demonstrates that the impairment of ACC LTD caused by tail amputation can be rescued by priming with the selective activation of mGluR1.

Because high concentrations of DHPG produced chemical LTD in sham slices, we decided to further test the priming effects with a lower concentration of DHPG (Fig. 9C,D). Priming with DHPG $(20 \mu \mathrm{M})$ and MPEP $(10 \mu \mathrm{M})$ did not produce any chemical
B AP5 $(50 \mu \mathrm{M})$

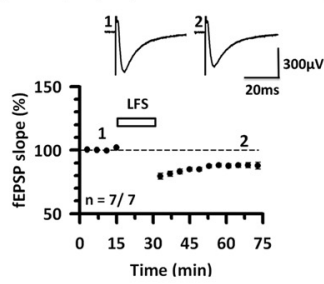

C Nimodipine (10 $\mu \mathrm{M})$

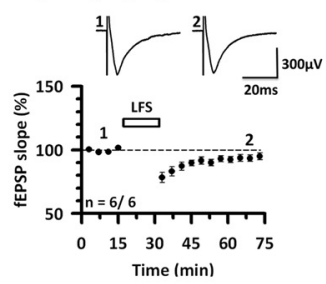

F $\mathrm{LY367385(100 \mu \textrm {M } )}$


\section{G}

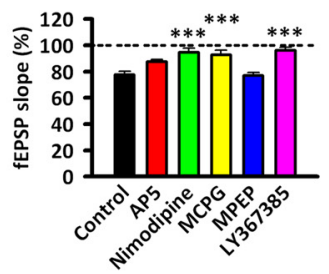

Figure 6. Pharmacological aspects of ACC LTD. $A$, Controls showed LTD after $1 \mathrm{~Hz}, 15$ min low-frequency stimulation (78 $\pm 2 \%$; blocker nimodipine (10 $\mu \mathrm{m}$ ) blocked LTD ( $95 \pm 3 \% ; n=6$ slices $/ 6$ mice). $D$, Group I and II mGluR antagonist MCPG (500 $\mu \mathrm{M})$ also the averaged fEPSP slope of the last 10 min of each experiment $\left(F_{(5,31)}=10.64, p<0.01\right.$; one-way ANOVA with Bonferroni post hoc; $p<0.001$ for control vs nimodipine, MCPG, and LY367385).

depression in both sham and tail-amputated mice ACC slices. However, subsequent low-frequency stimulation induced LTD in both sham (77 $\pm 6 \%, n=8$ slices $/ 8$ mice) and amputated animals ( $75 \pm 5 \%, n=7$ slices $/ 7$ mice).

\section{Protein kinase $\mathrm{C}$, but not $\mathrm{Ca}^{2+} /$ calmodulin-dependent protein kinase II or protein kinase $\mathrm{A}$, is important in rescuing} ACC LTD

To determine the mechanism of the metaplastic rescue in the ACC LTD, we performed pharmacological experiments using different protein kinase inhibitors (Fig. 10A-E). Protein kinase $\mathrm{C}(\mathrm{PKC})$ and $\mathrm{Ca}^{2+} /$ calmodulin-dependent protein kinase II (CaMKII) are important in metaplasticity of LTP in the hippocampus (Bortolotto and Collingridge, 1998, 2000). In addition, protein kinase A (PKA) is also implicated in hippocampal LTD and metaplasticity (Brandon et al., 1995; Qi et al., 1996; Oh et al., 2006; Abraham, 2008). Coapplication of a PKC inhibitor chelerythrine $(3 \mu \mathrm{M})$ with DHPG $(20 \mu \mathrm{M})$ and MPEP $(10 \mu \mathrm{M})$ during the priming period prevented the rescue of LTD in the ACC slices of amputated mice $(94 \pm 4 \% ; n=$ 9 slices/9 mice). By contrast, inhibiting CaMKII [KN 62 (10 $\mu \mathrm{M}) ; 83 \pm 3 \% ; n=9$ slices $/ 9$ mice] or PKA [KT $5720(1 \mu \mathrm{M})$; $76 \pm 4 \% ; n=9$ slices $/ 8$ mice) failed to prevent the rescue $\left(F_{(3,29)}=4.70, p=0.009\right.$; one-way ANOVA with Bonferroni post hoc; $p<0.05$ for vehicle vs chelerythrine). These results suggest that DHPG and MPEP priming can rescue the loss of LTD in the tail-amputated mice, and that PKC acts as a major factor in this process. 
A

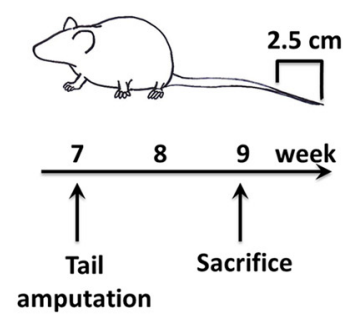

B Sham

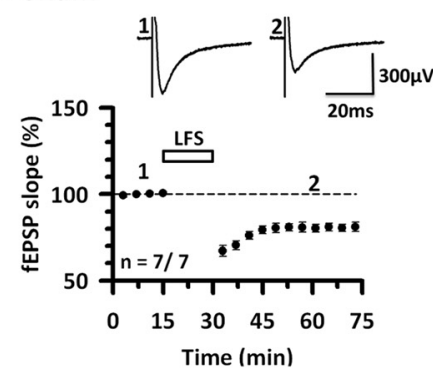

C Tail amputated



D Sham

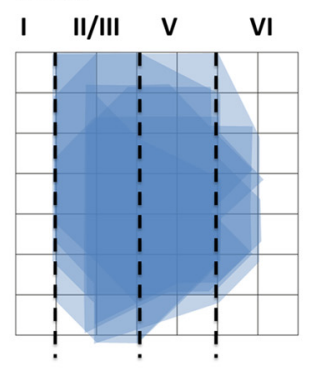

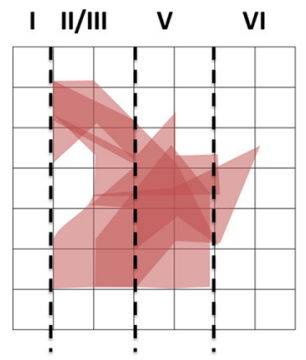

E Tail amputated

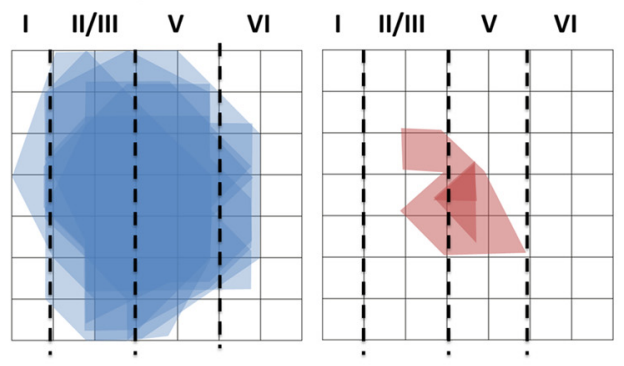

G Tail amputated

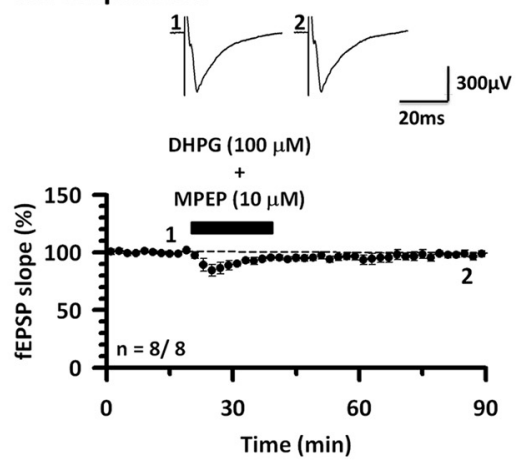

Figure 7. Tail amputation impairs ACC LTD. $\boldsymbol{A}$, The schematic view of tail amputation experiment process. $\boldsymbol{B}$, The sham groups showed similar $\mathrm{LTD}$ as the control group $(81 \pm 2 \% ; n=7$ slices $/ 7$ mice). $\boldsymbol{C}$, The 2 week tail-amputated group showed impaired ACCLTD ( $96 \pm 2 \% ; n=9$ slices $/ 9$ mice). $\boldsymbol{D}, \boldsymbol{E}$, The spatial distribution of activated channels during baseline (blue) and the channels that underwent LTD (red). The spatial distribution of activated channels during baseline in sham and amputated model is similar. However, sham group shows a wider distribution of LTD-occurring channels compared with the tail-amputated group, which rarely shows LTD near the stimulation site. $\boldsymbol{F}$, Sham showed normal chemical LTD by applying DHPG (100 $\mu \mathrm{M})$ and MPEP (10 $\mu \mathrm{M})$ for 20 $\min (86 \pm 4 \% ; n=7$ slices/7 mice). G, Twenty minutes after application of DHPG $(100 \mu \mathrm{M})$ and MPEP (10 $\mu \mathrm{M})$, the tail-amputated group showed no chemical LTD.

A

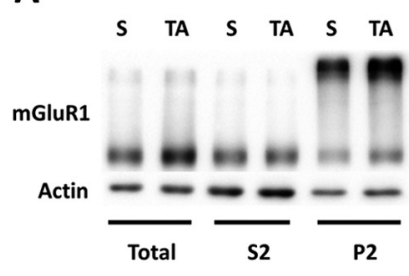

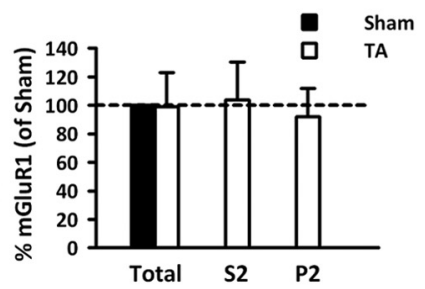

B

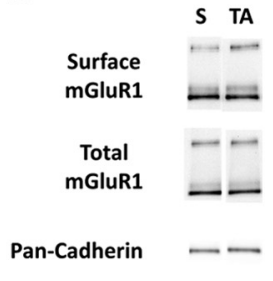

Figure 8. Biochemical analysis showed no difference in mGluR1 expression level in the ACC after tail amputation. $\boldsymbol{A}$, Western blot analysis of ACC slices for examining mGluR1 expression in sham and tail-amputated groups. Left, Representative data from one sample. Right, The averaged data of five samples. When normalized to actin, mGluR1 protein level in different fractions showed no difference between sham and tail-amputated groups (mGluR1 total, $99 \pm 24 \% ; S 2,103 \pm 26 \% ; P 2,92 \pm 20 \%, n=5$ samples/10 mice). Data are expressed by the percentage of sham to tail-amputated group. $\boldsymbol{B}$, Biotinylation analysis of ACC slices for surface mGluR1 level in sham and tail-amputated groups. Surface mGluR1 level did not show any difference between groups. S, sham; TA, tail-amputated.

vious report in adult rat ACC (Wei et al., 1999). Using an MEA system, we were able to show that LTD appeared in local circuits within the ACC when applying electrical stimulation to the deep layer $\mathrm{V}$. The induction of LTD was frequencydependent, with the maximal depression induced by repetitive stimulation delivered at $1 \mathrm{~Hz}$. Pharmacological experiments found that LTD required the activity of mGluR1 and L-VGCCs; while inhibiting NMDA receptors only partially reduced the induction of LTD. A chemical LTD, induced by the selective activation of mGluR1 (using coapplication of DHPG and MPEP), was also observed in the

\section{Discussion}

In this study we have demonstrated that low-frequency stimulation induces LTD in the adult mouse ACC, supporting the pre-
ACC. We found that tail amputation greatly impaired both lowfrequency stimulation-induced LTD and chemical LTD in the ACC. Priming ACC slices with bath application of pharmacolog- 
ical agents to selectively activate mGluR1 rescued the loss of LTD by amputation. Activation of PKC was required in this metaplastic LTD rescue, but activation of neither CaMKII nor PKA was required. Our results demonstrate that activation of mGluR1 in the ACC is critical for LTD, and raise the possibility that drugs that act on mGluR1 and its downstream signaling processes may help to treat phantom pain or associated brain dysfunctions.

\section{Mapping LTD in a cortical circuit}

MEA technology represents a valuable tool to record responses in numerous sites simultaneously for a long time (Oka et al., 1999; Morin et al., 2005; Hofmann and Bading, 2006). We have used a 64-channel MEA system, MED64, in mouse brain slices to study the spatial distribution of synaptic transmission and LTD in the ACC. Within the ACC, we observed spatial distribution of excitatory synaptic transmission when stimulating deep layer $\mathrm{V}$. This was the only area we could detect $>20$ channels with inward responses. Stimulating other areas, such as layer I or II/III, induced at most 10 channels of inward responses. Different responses to the test stimulation suggest that the synaptic responses we recorded are due to local synaptic networks, rather than general field responses from the same population of cells. Our results suggest, therefore, that certain local circuits in the brain slice preparation are intact. This conclusion is supported by a recent electrophysiological study using dual whole-cell patchclamp recording technique (Wu et al., 2009). We can conclude, therefore, that neurons within different layers of the ACC are highly interconnected within the brain slice preparation. We found, however, that not every activated channel underwent LTD; the channels within a $300 \mu \mathrm{m}$ radius of the stimulation site were the most likely to exhibit this form of synaptic plasticity.

\section{Mechanisms of ACC LTD}

Two major forms of LTD have been reported in the CNS: NMDA receptor-LTD and mGluR-LTD (Collingridge et al., 2010). Both forms of LTD have been reported in the ACC, depending on the induction protocol. Field recording using low-frequency stimulation in adult rat ACC induced mGluR-LTD (Wei et al., 1999), whereas whole-cell patch-clamp recording using a pairing protocol in adult mouse ACC induced NMDA receptor-LTD (Toyoda et al., 2005). Depolarizing the postsynaptic neuron during the pairing protocol promotes the activation of NMDA receptor and this could increase the chance for NMDA receptor-LTD in the ACC. It is known that both NMDA receptor-LTD (Dudek and Bear, 1992) and mGluR-LTD (Bashir et al., 1993b) can be observed in the same type of synapse and may coexist at the same developmental stage (Oliet et al., 1997). Our present study used single-shock low-frequency stimulation for LTD induction, and found that AP-5 only partially inhibited ACC LTD. The depression level of the quantified channels and
B

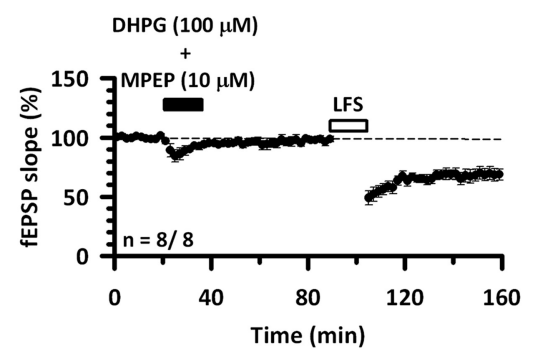

D Tail amputated

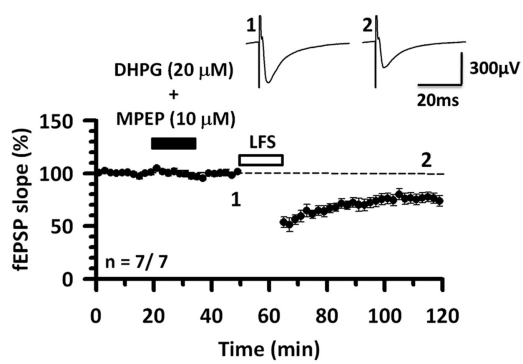

Figure 9. Recovery of ACC LTD in tail-amputated mice by priming. $A, B$, DHPG $(100 \mu \mathrm{M})$ and MPEP $(10 \mu \mathrm{M})$ were given together ring baseline for $20 \mathrm{~min}$ in the tail-amputated group. After washout for $50 \mathrm{~min}$, low-frequency stimulation of $1 \mathrm{~Hz}$ for $15 \mathrm{~min}$ was Iive for $15 \mathrm{~min}$, low-frequency stimulation of $1 \mathrm{~Hz}$ for 15 min was given. C, Sham ( $77 \pm 6 \% ; n=8$ slices/8 mice) showed LTD after priming. D, Tail-amputated (75 $\pm 5 \% ; n=7$ slices $/ 7$ mice) group also showed LTD.

the number of channels that underwent LTD in the presence of AP-5 were approximately half of those of the control group. However, the broad spectrum mGluR antagonist MCPG (Bashir et al., 1993a) blocked ACC LTD in terms of both the depression level and the number of channels showing LTD. These results suggest both NMDA receptors and mGluRs are involved in the ACC LTD in adult mice when repetitive low-frequency stimulation is given, but the latter have the more prominent role.

The role of group I mGluRs in synaptic plasticity has been extensively investigated in various regions of the brain. For example, at hippocampal CA1 synapses, DHPG-induced LTD involves mGluR5 (Palmer et al., 1997), whereas LTD at parallel fiber to Purkinje cell synapses in the cerebellum requires mGluR1 (Conquet et al., 1994). Our study suggests that mGluR1 is the major factor for lowfrequency stimulation-induced LTD in the ACC. Nimodipine also blocked low-frequency stimulation-induced LTD in the ACC. Our previous reports have already shown that L-VGCCs are important for both LTD (Wei et al., 1999) and LTP (Liauw et al., 2005) in adult rodent ACC. Calcium regulation is known to be important in synaptic plasticity and L-VGCCs provide one major route across the plasma membrane, where it is linked to gene expression (Dolmetsch et al., 2001; West et al., 2001). In addition, activation of L-VGCCs has been shown to directly facilitate the function of group I mGluRs (Rae et al., 2000). Therefore, it is not surprising to discover the role of L-VGCC in the ACC LTD, in particular one that also involves group I mGluRs.

\section{Loss of cortical LTD after amputation}

Cumulative animal and human studies demonstrate that the ACC, together with other related cortical areas, plays important roles in 
A Control

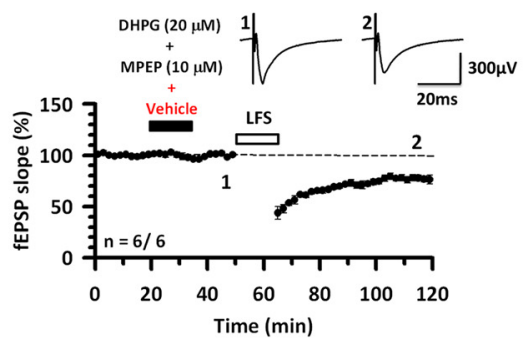

C CaMKII inhibitor

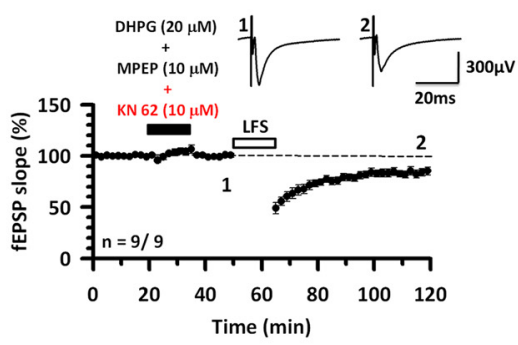

E



Figure 10. PKC but not PKA or CaMKII is necessary for the rescue of ACC LTD. DHPG $(20 \mu \mathrm{M})$, MPEP $(10 \mu \mathrm{M})$, and each specific drug were given together for $15 \mathrm{~min}$ in the tail-amputated mice. $A$, Vehicle group showed the rescue of LTD ( $77 \pm 3 \% ; n=6$ slices/ 6 mice). $\boldsymbol{B}$, PKC inhibitor chelerythrine $(3 \mu \mathrm{M}$ ) prevented the rescue of LTD in tail-amputated group ( $94 \pm 4 \% ; n=9$ slices $/ 9$ mice). C, CaMKIl inhibitor KN 62 (10 $\mu \mathrm{M})$ showed depression but less than that shown in vehicle group ( $83 \pm 3 \% ; n=9$ slices $/ 9$ mice). D, PKA inhibitor KT5720 ( $1 \mu \mathrm{m})$ did not prevent the rescue of LTD ( $76 \pm 4 \% ; n=9$ slices/8 mice). $\boldsymbol{E}$, Summary data of all the drugs tested in the current experiment $\left(F_{(3,29)}=4.70, p=0.009\right.$; one-way ANOVA with Bonferroni post hoc; $p<0.05$ for vehicle vs chelerythrine).

pain perception and chronic pain (Zhuo, 2008). Peripheral injuries, such as nerve injury or inflammation, trigger synaptic potentiation in the ACC pyramidal cells. Both presynaptic enhancement of glutamate release and postsynaptic amplification of AMPA receptor-mediated responses contribute to the potentiation (Xu et al., 2008; Zhuo, 2008; Li et al., 2010). For peripheral amputation, LTPlike potentiation has been reported in rats under anesthesia in vivo (Wei and Zhuo, 2001). In an especially noteworthy development, in vivo intracellular recordings have demonstrated that LTP likely occurs on excitatory synapses of cortical pyramidal cells in the ACC (Wu et al., 2005c). These studies provide a useful animal model for investigating cortical reorganization, long-term plastic changes within the cortex. Similar to previous studies in rats, our studies detected no LTD, induced by low-frequency stimulation, within the ACC after amputation (Wei et al., 1999). Furthermore, we also observed a loss of LTD induced by the pharmacological activation of mGluR1 following amputation. In both sets of experiments we identified mGluR1 as the subtype involved. However, our biochemical data showed that the surface level of mGluR1 was not changed after amputation compared with the sham group, suggesting that amputation-triggered loss of LTD is not due to reduction of postsynaptic membrane levels of mGluR1. The modification may therefore be downstream of the receptor. Future studies are clearly needed to map this pathway. However, we cannot rule out the possibility of slight change of mGluR1 surface level in only some subset of ACC cells. This could have induced the major difference in ACC LTD of the amputated mice, but the changes of mGluR1 level cannot be detected by our biochemical experiments.

Rescued LTD by priming with mGluRs An unusual feature of group I mGluRs is their role in metaplasticity, where their activation can affect subsequent synaptic plasticity (Abraham, 2008). For example, in the hippocampal formation, brief prior activation of group I mGluRs has been shown to facilitate LTP (Cohen et al., 1998), to enable the induction of a pharmacologically distinct form of LTP (Bortolotto et al., 1994), and to inhibit LTD (Wu et al., 2004). Our data suggest that low-frequency stimulation-induced LTD in the ACC is more mGluR1-dependent than mGluR5-dependent. Although our biochemical data show no change in membrane expression level of mGluR1, stimulating mGluR1 could work as a rescue target in tail-amputated mice LTD by activating the downstream pathway or the slightly changed surface mGluR1 in some subset of cells. We therefore applied DHPG and MPEP together to selectively activate mGluR1 in the amputated group and subsequently applied low-frequency stimulation after washout of DHPG and MPEP. To our surprise, this treatment was able to fully restore LTD. Moreover, $\mathrm{PKC}$ was necessary in this metaplastic rescue. By contrast, neither CaMKII nor PKA is required. Consistent with previous studies in the hippocampus (Bortolotto and Collingridge, 2000), PKC is required for metaplasticity of LTD in the ACC. Future studies are needed to identify the role of specific subtypes of PKC in this form of metaplasticity. In contrast to the metaplasticity of LTP in the hippocampus (Bortolotto and Collingridge, 1998), we found CaMKII was not required for this form of metaplasticity in the ACC, though its inhibition did tend to reduce the level of priming. Moreover, a recent study showed in the hippocampus that CaMKII was important in mediating DHPG-induced mGluR-LTD but not PKC (Mockett et al., 2011). These results indicate that intracellular mechanisms mediated by priming group I mGluR in LTD may be doserelated and region-dependent.

In summary, we have used an MEA approach to investigate the spatial distribution and the cortical circuitry involved in the mouse ACC and found that LTD was expressed in a networkdependent manner. Low-frequency stimulation-induced LTD in the ACC required the activation of both mGluR1 and L-VGCCs. In tail-amputated mice, LTD was greatly reduced in all the ACC layers, but could be fully rescued by the transient pharmacological activation of mGluR1 via a priming mechanism involving PKC. 


\section{References}

Abraham WC (2008) Metaplasticity: tuning synapses and networks for plasticity. Nat Rev Neurosci 9:387-399.

Apkarian AV, Bushnell MC, Treede RD, Zubieta JK (2005) Human brain mechanisms of pain perception and regulation in health and disease. Eur J Pain 9:463-484.

Bashir ZI, Bortolotto ZA, Davies CH, Berretta N, Irving AJ, Seal AJ, Henley JM, Jane DE, Watkins JC, Collingridge GL (1993a) Induction of LTP in the hippocampus needs synaptic activation of glutamate metabotropic receptors. Nature 363:347-350.

Bashir ZI, Jane DE, Sunter DC, Watkins JC, Collingridge GL (1993b) Metabotropic glutamate receptors contribute to the induction of longterm depression in the CA1 region of the hippocampus. Eur J Pharmacol 239:265-266.

Blake JF, Brown MW, Collingridge GL (1988) CNQX blocks acidic amino acid induced depolarizations and synaptic components mediated by nonNMDA receptors in rat hippocampal slices. Neurosci Lett 89:182-186.

Bliss TV, Cooke SF (2011) Long-term potentiation and long-term depression: a clinical perspective. Clinics (Sao Paulo) 66 [Suppl 1]:3-17.

Bortolotto ZA, Collingridge GL (1998) Involvement of calcium/ calmodulin-dependent protein kinases in the setting of a molecular switch involved in hippocampal LTP. Neuropharmacology 37:535544.

Bortolotto ZA, Collingridge GL (2000) A role for protein kinase C in a form of metaplasticity that regulates the induction of long-term potentiation at CA1 synapses of the adult rat hippocampus. Eur J Neurosci 12:40554062.

Bortolotto ZA, Bashir ZI, Davies CH, Collingridge GL (1994) A molecular switch activated by metabotropic glutamate receptors regulates induction of long-term potentiation. Nature 368:740-743.

Brandon EP, Zhuo M, Huang YY, Qi M, Gerhold KA, Burton KA, Kandel ER, McKnight GS, Idzerda RL (1995) Hippocampal long-term depression and depotentiation are defective in mice carrying a targeted disruption of the gene encoding the RI beta subunit of cAMP-dependent protein kinase. Proc Natl Acad Sci U S A 92:8851-8855.

Brebner K, Wong TP, Liu L, Liu Y, Campsall P, Gray S, Phelps L, Phillips AG, Wang YT (2005) Nucleus accumbens long-term depression and the expression of behavioral sensitization. Science 310:1340-1343.

Cohen AS, Raymond CR, Abraham WC (1998) Priming of long-term potentiation induced by activation of metabotropic glutamate receptors coupled to phospholipase C. Hippocampus 8:160-170.

Collingridge GL, Peineau S, Howland JG, Wang YT (2010) Long-term depression in the CNS. Nat Rev Neurosci 11:459-473.

Conquet F, Bashir ZI, Davies CH, Daniel H, Ferraguti F, Bordi F, Franz-Bacon K, Reggiani A, Matarese V, Condé F, et al. (1994) Motor deficit and impairment of synaptic plasticity in mice lacking mGluR1. Nature 372:237-243.

Craig AD, Reiman EM, Evans A, Bushnell MC (1996) Functional imaging of an illusion of pain. Nature 384:258-260.

de Tommaso M, Losito L, Difruscolo O, Libro G, Guido M, Livrea P (2005) Changes in cortical processing of pain in chronic migraine. Headache 45:1208-1218.

Dölen G, Osterweil E, Rao BS, Smith GB, Auerbach BD, Chattarji S, Bear MF (2007) Correction of fragile X syndrome in mice. Neuron 56:955-962.

Dolmetsch RE, Pajvani U, Fife K, Spotts JM, Greenberg ME (2001) Signaling to the nucleus by an L-type calcium channel-calmodulin complex through the MAP kinase pathway. Science 294:333-339.

Dudek SM, Bear MF (1992) Homosynaptic long-term depression in area CA1 of hippocampus and effects of N-methyl-D-aspartate receptor blockade. Proc Natl Acad Sci U S A 89:4363-4367.

Dunckley P, Wise RG, Aziz Q, Painter D, Brooks J, Tracey I, Chang L (2005) Cortical processing of visceral and somatic stimulation: differentiating pain intensity from unpleasantness. Neuroscience 133:533-542.

Eisenberger NI, Lieberman MD, Williams KD (2003) Does rejection hurt? An FMRI study of social exclusion. Science 302:290-292.

Hofmann F, Bading H (2006) Long term recordings with microelectrode arrays: studies of transcription-dependent neuronal plasticity and axonal regeneration. J Physiol Paris 99:125-132.

Hutchison WD, Davis KD, Lozano AM, Tasker RR, Dostrovsky JO (1999) Pain-related neurons in the human cingulate cortex. Nat Neurosci 2:403-405.

Kim JI, Lee HR, Sim SE, Baek J, Yu NK, Choi JH, Ko HG, Lee YS, Park SW,
Kwak C, Ahn SJ, Choi SY, Kim H, Kim KH, Backx PH, Bradley CA, Kim E, Jang DJ, Lee K, Kim SJ,et al. (2011) PI3Kgamma is required for NMDA receptor-dependent long-term depression and behavioral flexibility. Nat Neurosci 14:1447-1454.

Kirkwood A, Dudek SM, Gold JT, Aizenman CD, Bear MF (1993) Common forms of synaptic plasticity in the hippocampus and neocortex in vitro. Science 260:1518-1521.

Liauw J, Wu LJ, Zhuo M (2005) Calcium-stimulated adenylyl cyclases required for long-term potentiation in the anterior cingulate cortex. J Neurophysiol 94:878-882.

Li XY, Ko HG, Chen T, Descalzi G, Koga K, Wang H, Kim SS, Shang Y, Kwak C, Park SW, Shim J, Lee K, Collingridge GL, Kaang BK, Zhuo M (2010) Alleviating neuropathic pain hypersensitivity by inhibiting PKMzeta in the anterior cingulate cortex. Science 330:1400-1404.

Manahan-Vaughan D, Braunewell KH (1999) Novelty acquisition is associated with induction of hippocampal long-term depression. Proc Natl Acad Sci U S A 96:8739-8744.

Mockett BG, Guévremont D, Wutte M, Hulme SR, Williams JM, Abraham WC (2011) Calcium/calmodulin-dependent protein kinase II mediates group I metabotropic glutamate receptor-dependent protein synthesis and long-term depression in rat hippocampus. J Neurosci 31:7380-7391.

Morin FO, Takamura Y, Tamiya E (2005) Investigating neuronal activity with planar microelectrode arrays: achievements and new perspectives. J Biosci Bioeng 100:131-143.

Mulkey RM, Malenka RC (1992) Mechanisms underlying induction of homosynaptic long-term depression in area CA1 of the hippocampus. Neuron 9:967-975.

Nicholls RE, Alarcon JM, Malleret G, Carroll RC, Grody M, Vronskaya S, Kandel ER (2008) Transgenic mice lacking NMDAR-dependent LTD exhibit deficits in behavioral flexibility. Neuron 58:104-117.

Oh MC, Derkach VA, Guire ES, Soderling TR (2006) Extrasynaptic membrane trafficking regulated by GluR1 serine 845 phosphorylation primes AMPA receptors for long-term potentiation. J Biol Chem 281:752-758.

Oka H, Shimono K, Ogawa R, Sugihara H, Taketani M (1999) A new planar multielectrode array for extracellular recording: application to hippocampal acute slice. J Neurosci Methods 93:61-67.

Oliet SH, Malenka RC, Nicoll RA (1997) Two distinct forms of long-term depression coexist in CA1 hippocampal pyramidal cells. Neuron 18:969-982.

Palmer MJ, Irving AJ, Seabrook GR, Jane DE, Collingridge GL (1997) The group I mGlu receptor agonist DHPG induces a novel form of LTD in the CA1 region of the hippocampus. Neuropharmacology 36:1517-1532.

Pillay PK, Hassenbusch SJ (1992) Bilateral MRI-guided stereotactic cingulotomy for intractable pain. Stereotact Funct Neurosurg 59:33-38.

Qi M, Zhuo M, Skålhegg BS, Brandon EP, Kandel ER, McKnight GS, Idzerda RL (1996) Impaired hippocampal plasticity in mice lacking the Cbetal catalytic subunit of cAMP-dependent protein kinase. Proc Natl Acad Sci U S A 93:1571-1576.

Rae MG, Martin DJ, Collingridge GL, Irving AJ (2000) Role of $\mathrm{Ca}^{2+}$ stores in metabotropic L-glutamate receptor-mediated supralinear $\mathrm{Ca}^{2+}$ signaling in rat hippocampal neurons. J Neurosci 20:8628-8636.

Rainville P, Duncan GH, Price DD, Carrier B, Bushnell MC (1997) Pain affect encoded in human anterior cingulate but not somatosensory cortex. Science 277:968-971.

Sajikumar S, Korte M (2011) Metaplasticity governs compartmentalization of synaptic tagging and capture through brain-derived neurotrophic factor (BDNF) and protein kinase Mzeta (PKMzeta). Proc Natl Acad Sci U S A 108:2551-2556.

Singer T, Seymour B, O’Doherty J, Kaube H, Dolan RJ, Frith CD (2004) Empathy for pain involves the affective but not sensory components of pain. Science 303:1157-1162.

Strigo IA, Duncan GH, Boivin M, Bushnell MC (2003) Differentiation of visceral and cutaneous pain in the human brain. J Neurophysiol 89:3294-3303.

Talbot JD, Marrett S, Evans AC, Meyer E, Bushnell MC, Duncan GH (1991) Multiple representations of pain in human cerebral cortex. Science 251:1355-1358.

Toyoda H, Zhao MG, Zhuo M (2005) Roles of NMDA receptor NR2A and NR2B subtypes for long-term depression in the anterior cingulate cortex. Eur J Neurosci 22:485-494.

Toyoda H, Wu LJ, Zhao MG, Xu H, Jia Z, Zhuo M (2007) Long-term de- 
pression requires postsynaptic AMPA GluR2 receptor in adult mouse cingulate cortex. J Cell Physiol 211:336-343.

Vogt BA (2005) Pain and emotion interactions in subregions of the cingulate gyrus. Nat Rev Neurosci 6:533-544.

Wang H, Xu H, Wu LJ, Kim SS, Chen T, Koga K, Descalzi G, Gong B, Vadakkan KI, Zhang X, Kaang BK, Zhuo M (2011) Identification of an adenylyl cyclase inhibitor for treating neuropathic and inflammatory pain. Sci Transl Med 3:65ra63.

Wei F, Zhuo M (2001) Potentiation of sensory responses in the anterior cingulate cortex following digit amputation in the anaesthetised rat. J Physiol 532:823-833.

Wei F, Li P, Zhuo M (1999) Loss of synaptic depression in mammalian anterior cingulate cortex after amputation. J Neurosci 19:9346-9354.

Wei F, Qiu CS, Kim SJ, Muglia L, Maas JW, Pineda VV, Xu HM, Chen ZF, Storm DR, Muglia LJ, Zhuo M (2002) Genetic elimination of behavioral sensitization in mice lacking calmodulin-stimulated adenylyl cyclases. Neuron 36:713-726.

West AE, Chen WG, Dalva MB, Dolmetsch RE, Kornhauser JM, Shaywitz AJ, Takasu MA, Tao X, Greenberg ME (2001) Calcium regulation of neuronal gene expression. Proc Natl Acad Sci U S A 98:11024-11031.

Wong ET, Gunes S, Gaughan E, Patt RB, Ginsberg LE, Hassenbusch SJ, Payne R (1997) Palliation of intractable cancer pain by MRI-guided cingulotomy. Clin J Pain 13:260-263.

Wu J, Rowan MJ, Anwyl R (2004) Synaptically stimulated induction of group I metabotropic glutamate receptor-dependent long-term depression and depotentiation is inhibited by prior activation of metabotropic glutamate receptors and protein kinase C. Neuroscience 123:507-514.

Wu LJ, Zhao MG, Toyoda H, Ko SW, Zhuo M (2005a) Kainate receptor- mediated synaptic transmission in the adult anterior cingulate cortex. J Neurophysiol 94:1805-1813.

Wu LJ, Toyoda H, Zhao MG, Lee YS, Tang J, Ko SW, Jia YH, Shum FW, Zerbinatti CV, Bu G, Wei F, Xu TL, Muglia LJ, Chen ZF, Auberson YP, Kaang BK, Zhuo M (2005b) Upregulation of forebrain NMDA NR2B receptors contributes to behavioral sensitization after inflammation. J Neurosci 25:11107-11116.

Wu LJ, Li X, Chen T, Ren M, Zhuo M (2009) Characterization of intracortical synaptic connections in the mouse anterior cingulate cortex using dual patch-clamp recording. Mol Brain 2:32.

Wu MF, Pang ZP, Zhuo M, Xu ZC (2005c) Prolonged membrane potential depolarization in cingulate pyramidal cells after digit amputation in adult rats. Mol Pain 1:23.

Xu H, Wu LJ, Wang H, Zhang X, Vadakkan KI, Kim SS, Steenland HW, Zhuo M (2008) Presynaptic and postsynaptic amplifications of neuropathic pain in the anterior cingulate cortex. J Neurosci 28:7445-7453.

Yen CP, Kung SS, Su YF, Lin WC, Howng SL, Kwan AL (2005) Stereotactic bilateral anterior cingulotomy for intractable pain. J Clin Neurosci 12:886-890.

Yen CP, Kuan CY, Sheehan J, Kung SS, Wang CC, Liu CK, Kwan AL (2009) Impact of bilateral anterior cingulotomy on neurocognitive function in patients with intractable pain. J Clin Neurosci 16:214-219.

Zhuo M (2006) Molecular mechanisms of pain in the anterior cingulate cortex. J Neurosci Res 84:927-933.

Zhuo M (2008) Cortical excitation and chronic pain. Trends Neurosci 31:199-207.

Zhuo M (2011) Cortical plasticity as a new endpoint measurement for chronic pain. Mol Pain 7:54. 